\title{
Nitrogênio e potássio em milho irrigado: análise técnica e econômica da fertilização
}

\author{
Nitrogen and potassium in irrigated corn: technical and economic analysis of the fertilization
}

\author{
Paulo Sérgio Pavinato ${ }^{\mathrm{I}}$ Carlos Alberto Ceretta ${ }^{\mathrm{II}}$ Eduardo Girotto ${ }^{\mathrm{II}}$ \\ Isabel Cristina Lopes MoreiraII
}

\section{RESUMO}

A irrigação das culturas aumenta a possibilidade de obtenção de altas produtividades, mas exige racionalidade técnica e econômica no uso de insumos, especialmente fertilizantes nitrogenados. O objetivo deste trabalho foi determinar as doses mais adequadas de nitrogênio e de potássio para maior produtividade de grãos e o melhor retorno econômico da adubação com o cultivo de milho (Zea mays L.) sob irrigação por aspersão. $O$ experimento foi conduzido nos anos agrícolas 2002/03 e 2003/04, em Cruz Alta, Rio Grande do Sul, em lavoura sob irrigação com pivô central, em Latossolo Vermelho distrófico típico. A população efetiva do milho foi de 78.000 e 71.000 plantas $\mathrm{ha}^{-1} \mathrm{em} \mathrm{2002/03}$ e 2003/04, respectivamente, utilizando-se o híbrido Pioneer 30F44. Os tratamentos foram compostos das doses de 0, 80, 120, 160, 200 e $240 \mathrm{~kg} \mathrm{ha}^{-1}$ de $N$ (uréia) combinadas com 0 , 40, 80 e $120 \mathrm{~kg} \mathrm{ha}^{-1}$ de $\mathrm{K}_{2} \mathrm{O}$ (cloreto de potássio). O delineamento utilizado foi blocos ao acaso com quatro repetições. A máxima produtividade de grãos de milho sob irrigação por aspersão foi obtida com a aplicação de 283 a $289 \mathrm{~kg} \mathrm{ha}^{-1}$ de nitrogênio, mas a máxima eficiência econômica ocorreu com 156 a $158 \mathrm{~kg}$ $h a^{-1}$ de nitrogênio, não havendo incremento na produtividade com a aplicação de potássio. Isso evidencia que, em muitas situações, os produtores estão utilizando fertilizantes nitrogenados e potássicos acima do necessário.

Palavras-chave: doses de nitrogênio, doses de potássio, máxima eficiência técnica, máxima eficiência econômica, adubação do milho, irrigação.

\section{ABSTRACT}

Irrigation increases the probability to obtain high crop grain yield, but demands a technical and economical reasonable use of agricultural inputs, especially nitrogen fertilizers. The objective was to determine the more adequate rates of nitrogen and potassium for corn (Zea mays L.) grain yield and the better economical return of the fertilization in corn under sprinkle irrigation. The experiment was carried out in the years 2002/03 and 2003/04 in Cruz Alta-RS, Brazil, in a crop farm using central pivot irrigation system. The soil used was an Oxisol (Hapludox). The corn effective population totalized 78.000 and 71.000 plants $\mathrm{ha}^{-1}$ for the years 2002/03 and 2003/04, respectively, using the hybrid Pioneer 30F44. The treatments were composed by 0, 80, 120, 160, 200 and $240 \mathrm{~kg} \mathrm{ha}^{-1}$ of $N$ (urea) combined with $0,40,80$ and $120 \mathrm{~kg} \mathrm{ha}^{-1}$ of $\mathrm{K}_{2} \mathrm{O}$ (potassium chloride). The experiment was set in a randomized block design with four replicates. The maximum corn grain yield under sprinkle irrigation was obtained with $N$ rates between 283 and $289 \mathrm{~kg} \mathrm{ha}^{-1}$, but the maximum economic efficiency was between 156 and $158 \mathrm{~kg}$ of $N \mathrm{ha}^{-1}$, without any increment in grain yield with potassium application. These results show that, in many situations, farmers are using rates of nitrogen and potassium fertilizers over than necessary.

Key words: nitrogen rates, potassium rates, maximum technical efficiency, maximum economic efficiency, corn fertilization, irrigation.

\section{INTRODUÇÃO}

A produção brasileira de milho tem aumentado muito nos últimos anos e deverá aumentar ainda mais devido ao estímulo do seu uso para a produção de álcool. O milho também tem importante papel na rotação de culturas com a soja, especialmente em áreas sob plantio direto. Além disso, o milho constitui cultura básica da agricultura brasileira, pois envolve um contingente significativo de mão-de-obra rural no processo produtivo (FORNASIERI, 1992).

A distribuição irregular ou insuficiente de chuvas é um dos principais limitantes à produção

\footnotetext{
IDepartamento de Agronomia, Universidade Estadual do Centro-Oeste (UNICENTRO), Guarapuava, PR, Brasil.

IDepartamento de Solos, Universidade Federal de Santa Maria (UFSM), 97105-900, Santa Maria, RS, Brasil. Fone: (55) 3220

8108. E-mail: carlosceretta@smail.ufsm.br. *Autor para correspondência.
} 
agrícola no Brasil. Nos últimos anos, tem aumentado significativamente o cultivo do milho sob irrigação, promovendo algumas alterações nas formas de manejo das lavouras, através do planejamento de uso mais intensivo das áreas para compensação do alto investimento, com maior número de cultivos e culturas envolvidas e possibilidade de uso de doses mais elevadas de fertilizantes. Como em áreas irrigadas os riscos de quebra na produção são minimizados, os produtores tendem a utilizar fertilizantes em quantidades mais elevadas e até acima das recomendadas, na expectativa de aumento de produtividade. Neste sentido, lavouras sob irrigação devem ser planejadas visando maiores retornos econômicos da produção e menor impacto no ambiente, pois os prejuízos ambientais do uso excessivo de fertilizantes, especialmente nitrogenados, são grandes (LINK et al., 2006).

No Brasil, em 2001, de um total de 53,5 milhões de hectares cultivados com culturas anuais, principalmente milho e soja, cerca de 3,15 milhões foram cultivados sob irrigação, sendo que destes, $650 \mathrm{mil}$ foram com pivô central (CHRISTOFIDIS, 2002). O aumento de áreas irrigadas permite incrementos na produção sem aumentar a área cultivada, pois ameniza um dos principais fatores de limitação da produtividade de grãos das culturas que é a falta de água, especialmente para o milho.

No cenário mundial, o Brasil situa-se como o terceiro maior produtor de milho. Apesar do alto potencial produtivo desta cultura, evidenciado por produtividades de grãos de até $16.000 \mathrm{~kg} \mathrm{ha}^{-1}$, alcançados em condições experimentais e por agricultores tecnificados (CANTARELLA, 1993), a produtividade média no Brasil é de apenas $3.000 \mathrm{~kg} \mathrm{ha}^{-1}$, muito baixa quando comparada com produtividades de 8.670 e $4.700 \mathrm{~kg} \mathrm{ha}^{-1}$, obtidas nos Estados Unidos e na China, principais produtores desta cultura, respectivamente (ARAUJO et al., 2004). Resultados têm mostrado que o nitrogênio é o nutriente exigido em maior quantidade pela cultura do milho, sendo o que mais freqüentemente limita a produtividade de grãos. Enquanto no Brasil a quantidade média de $\mathrm{N}$ usada é $60 \mathrm{~kg} \mathrm{ha}^{-1}$, nos Estados Unidos e na China, é 150 e $130 \mathrm{~kg}$ ha $^{-1}$, respectivamente (ARAUJO et al., 2004).

O nitrogênio é um dos principais nutrientes para praticamente todas as culturas. Para o milho, ele desempenha papel importante no acúmulo de proteína e na produtividade de grãos. A disponibilidade de $\mathrm{N}$ no solo para as plantas é controlada basicamente pela decomposição da matéria orgânica e por adubações nitrogenadas, sendo que, quando são utilizadas culturas com baixa relação $\mathrm{C}: \mathrm{N}$ na matéria seca, em rotação, a decomposição e a mineralização é mais rápida e a ciclagem do $\mathrm{N}$ ocorre em curto espaço de tempo, como ocorre com as leguminosas. Também deve ser considerado aqui que as perdas de $\mathrm{N}$ no solo são altas, principalmente por lixiviação, na forma de nitrato, pois este nutriente não forma ligações fortes com as cargas permanentes do solo suficientes para reter o nitrato nas camadas de exploração radicular.

O potássio é o mineral mais abundante no tecido vegetal de praticamente todas as espécies vegetais e, por apresentar-se predominantemente na forma iônica $\mathrm{K}^{+}$no tecido, seu retorno ao solo é muito rápido, ocorre logo após a senescência das plantas. Assim, a maior parte do potássio é ciclada, embora possa ocorrer perda por lixiviação, principalmente quando se trata de solos arenosos. Contudo, deve-se considerar que estas perdas não são tão significativas no plantio direto porque este sistema favorece o acúmulo nas camadas mais superficiais do solo (PAVINATO, 2004). Nestes casos, as perdas podem se mostrar mais expressivas por escoamento superficial devido à manutenção da palhada sobre o solo e às aplicações superficiais de fertilizantes potássicos.

Devido à difusão do cultivo de milho irrigado e, com isso, a utilização de maiores doses de fertilizantes pelos produtores, o trabalho objetivou determinar a dose mais adequada de nitrogênio e potássio para produtividade de grãos e o melhor retorno econômico da adubação com o cultivo de milho sob irrigação por aspersão.

\section{MATERIAL E MÉTODOS}

O trabalho foi conduzido nos anos agrícolas 2002/03 e 2003/04, em parceria com a Pioneer Sementes Ltda, em áreas experimentais na região de Cruz Alta, Rio Grande do Sul. O solo é classificado como Latossolo Vermelho distrófico típico (EMBRAPA, 1999). Os experimentos foram conduzidos em área sob irrigação por aspersão com pivô central e sob o sistema plantio direto há mais de 10 anos. Nos últimos anos a rotação de culturas predominante nestas áreas foi a soja e milho no verão, intercalada com aveia preta no inverno.

As principais características químicas do solo na instalação dos experimentos, na profundidade de $0-10 \mathrm{~cm}$, eram as seguintes: $\mathrm{pH}_{\mathrm{H} 2 \mathrm{O}}: 5,2$ e 5,1; 37 e $38 \mathrm{~g}$ $\mathrm{dm}^{-3}$ de MO; 10,5 e 16,3mg dm${ }^{-3}$ de P; 198 e $168 \mathrm{mg} \mathrm{dm}^{-3}$ de K; 0,3 e 0,4cmol dm $\mathrm{dm}^{-3} \mathrm{de} \mathrm{Al;} 4,8$ e 4,2 $\mathrm{cmol}_{\mathrm{c}} \mathrm{dm}^{-3} \mathrm{de}$ Ca; 2,2 e 1,7 $\mathrm{cmol}_{c} \mathrm{dm}^{-3}$ de Mg; e saturação por bases de 64 e 53\% para os anos 2002/03 e 2003/04, respectivamente. Os teores de fósforo e potássio do solo nos dois anos eram interpretados como alto e muito alto, respectivamente, conforme CQFS-RS/SC (2004). 
O delineamento experimental utilizado foi de blocos ao acaso, com quatro repetições. As unidades experimentais constituiram-se de parcelas de 5 x $5 \mathrm{~m}$. As semeaduras foram realizadas com uso de semeadora tratorizada, equipada com sulcador de discos duplos, no espaçamento de $0,70 \mathrm{~m}$ entre linhas, e espalhando cinco sementes por metro linear, no mês de outubro de cada ano, com população efetiva final de 78.000 e 71.000 plantas ha-1, para as safras de 2002/03 e 2003/04, respectivamente. O híbrido utilizado foi o Pioneer 30F44 para os dois anos. Os tratamentos foram alocados na forma bifatorial, combinando seis doses de $\mathrm{N}(0,80$, 120, 160, 200 e $240 \mathrm{~kg} \mathrm{ha}^{-1}$ ) na forma de uréia, com quatro doses de $\mathrm{K}_{2} \mathrm{O}\left(0,40,80\right.$ e $\left.120 \mathrm{~kg} \mathrm{ha}^{-1}\right)$ na forma de cloreto de potássio, ambos granulares. As adubações potássica e nitrogenada foram parceladas, sendo aplicados $40 \mathrm{~kg} \mathrm{ha}^{-1}$ de $\mathrm{K}_{2} \mathrm{O}$ e $\mathrm{N}$ no momento da semeadura, locadas $0,05 \mathrm{~m}$ lateralmente à linha da semente e a $0,03 \mathrm{~m}$ de profundidade. A adubação nitrogenada foi completada com uma cobertura para as doses de até $120 \mathrm{~kg} \mathrm{ha}^{-1}$ de $\mathrm{N}$ e duas coberturas (50\% + $50 \%$ ) para as doses maiores, sendo a primeira feita com 4 a 5 folhas completamente abertas e a segunda com 8 a 10 folhas abertas do milho. O restante do $\mathrm{K}_{2} \mathrm{O}$ necessário para completar os tratamentos foi aplicado juntamente com a primeira cobertura de N. As adubações de cobertura foram realizadas manualmente, com aplicação próxima à linha da cultura, sem incorporação, mas em dia chuvoso e com solo úmido.

Anteriormente à semeadura, foi realizada uma dessecação da aveia preta (cultura antecessora) com uso de glifosate. Durante o cultivo, foi realizada uma aplicação de herbicida pós-emergente (Sanson), quando o milho se encontrava com 5-6 folhas abertas, e posteriormente realizou-se capina manual. Também foi realizada uma aplicação de inseticida para controle da lagarta do cartucho.

A produtividade de grãos de milho foi determinada pela colheita manual da área útil das parcelas (4 linhas internas e 4m de comprimento), com posterior trilha, pesagem e coleta de amostras para determinação de umidade e impurezas. A produtividade foi corrigida para zero de impurezas e 13\% de umidade.

A análise econômica da produtividade foi realizada considerando-se os insumos, maquinário e mão-de-obra e ainda custos com outros itens envolvidos indiretamente no processo produtivo, como depreciação, despesas administrativas, juros e outros. Estes últimos foram baseados em dados obtidos com a produção de milho irrigado pela Empresa SLC Agrícola Ltda na Fazenda Paineira, localizada em Coronel Bicaco, Rio Grande do Sul, e gentilmente fornecidos para a análise econômica nos experimentos. Contudo, os custos com sementes, fertilizantes e defensivos foram baseados em valores obtidos em empresas distribuidoras da região de Cruz Alta. Além disso, foi computado o custo dos fertilizantes em cada situação, considerando-se os preços dos fertilizantes, e das sementes no mês de outubro de 2002 e 2003, período no qual, normalmente, seriam adquiridos estes produtos pelos produtores. A análise econômica foi baseada na receita total menos o custo total de produção, em US\$, em cada situação, considerando-se a venda da produção na segunda quinzena de junho em 2003 e 2004, pois esse período do ano normalmente corresponde àquele em que o produtor vende a sua produção. A conversão do dólar foi considerada pela média do câmbio nos referidos meses de compra dos insumos e venda do produto.

Os dados foram submetidos à análise de variância pelo programa Statistical Analysis System (SAS INSTITUTE, 1996), sendo efetuado estudo de regressão para os fatores com significância a 5\% de probabilidade de erro.

\section{RESULTADOS E DISCUSSÃO}

A produtividade de grãos de milho não foi afetada pela aplicação de potássio. Isso pode se justificar pelos altos teores disponíveis de $\mathrm{K}$ no solo (CERETTA \& PAVINATO, 2003). No entanto, houve incremento com as doses de N (Figura 1), sem apresentar interação significativa entre os fertilizantes potássico e nitrogenado.

Em lavouras irrigadas, pode-se aumentar os níveis de adubação, pois os riscos de perda de produtividade por déficit hídrico são minimizados (CERETTA \& SILVEIRA, 2001). Neste trabalho, a aplicação de doses crescentes de $\mathrm{N}$ resultou no incremento da produtividade de grãos nos dois anos agrícolas (Figura 1). A máxima eficiência técnica em produtividade de grãos, de acordo com a equação ajustada, seria atingida com a aplicação de 283 e $289 \mathrm{~kg}$ ha $^{-1}$ de $\mathrm{N}$ em 2002/03 e 2003/04, respectivamente, considerando-se a média da produtividade com as quatro doses de $\mathrm{K}_{2} \mathrm{O}$. Estas quantidades de $\mathrm{N}$ estão acima dos $243 \mathrm{~kg} \mathrm{ha}^{-1}$ de $\mathrm{N}$ obtido por MENDONÇA et al. (1999), que utilizaram modelos matemáticos aplicados a experimentos com $\mathrm{N}$ em milho, e dos $226 \mathrm{~kg}$ ha $^{-1}$ de N, obtido por SILVEIRA(2002) na safra de 2000/ 01, também na região de Cruz Alta, RS.

Deve-se ressaltar que essas quantidades de $\mathrm{N}$ para a obtenção da máxima eficiência de produtividade de grãos é observada em condições de cultivo irrigado, podendo diminuir muito em condições de sequeiro. Exemplo disso é a maior produtividade de milho com $147 \mathrm{~kg} \mathrm{ha}^{-1}$ de $\mathrm{N}$, em plantio direto sem irrigação, no cerrado brasileiro, obtido por FERNANDES 


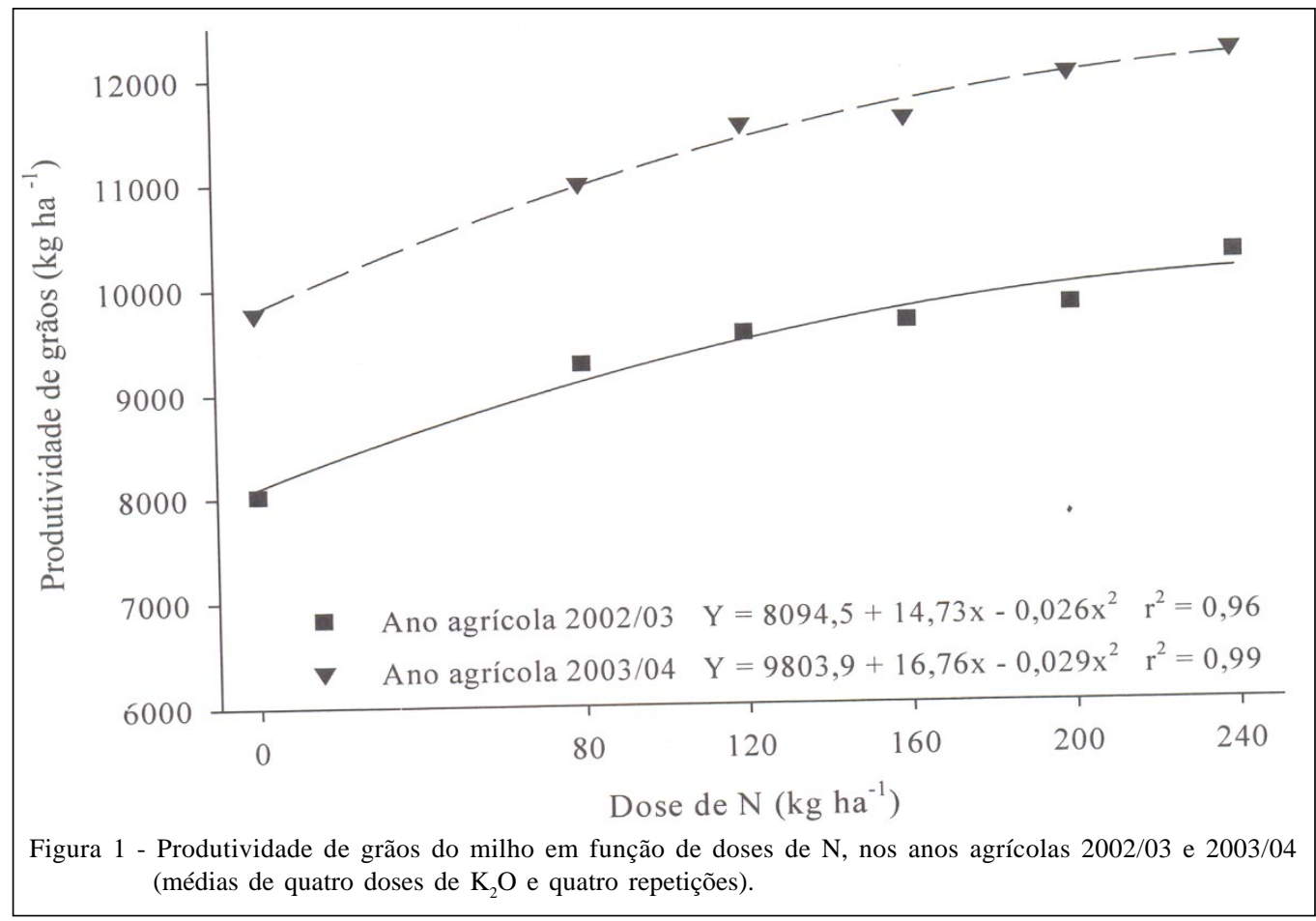

et al. (1999) e, na região de Ilha Solteira, SP, onde SILVA et al. (2005) mostraram que a máxima produtividade de milho em sequeiro foi alcançada com a dose de $166 \mathrm{~kg}$ $\mathrm{ha}^{-1}$ de N. Em outro experimento nessa mesma região, a máxima eficiência técnica foi alcançada com doses entre 144 e $174 \mathrm{~kg} \mathrm{ha}^{-1}$ de $\mathrm{N}$ e a variação ocorreu em resposta à cultura de cobertura usada anteriormente, sempre com resposta quadrática às doses de N (SILVA et al., 2006). Dados semelhantes também foram observados por FERNANDES et al. (1999) em experimento com doses de $\mathrm{N}$, em sistemas de manejo, apresentando valores de 147 a $168 \mathrm{~kg} \mathrm{ha}^{-1}$ de $\mathrm{N}$ para a máxima produtividade de grãos de milho sobre sistemas de manejo, com melhores respostas no sistema plantio direto.

A produtividade de milho é influenciada pela cultura anterior, que tem reflexos na adubação nitrogenada para o milho (CQFS-RS/SC, 2004). As doses de $\mathrm{N}$ recomendadas para o milho são bem menores quando a cultura anterior é uma leguminosa, se comparada a uma gramínea (AMADO et al., 2002). Nos dois anos desse trabalho foi cultivada a gramínea aveia preta antes do milho, refletindo a realidade de grande parte das lavouras no Sul do Brasil, pois a aveia preta proporciona grande aporte de matéria seca para ciclagem de nutrientes e manutenção de resíduos na superfície do solo. Entretanto, a quantidade de resíduo da matéria seca de aveia preta, quando da semeadura do milho, variou de 850 a $1100 \mathrm{~kg} \mathrm{ha}^{-1}$ nos dois anos, sugerindo pouco efeito de imobilização microbiana de $\mathrm{N}$.
É oportuno lembrar que, quando o cultivo do milho destina-se à silagem, a produção de matéria seca e o acúmulo de nutrientes na parte aérea passam a ser importantes e são influenciados pelas doses de N. Exemplo disso é o trabalho de PAVINATO (2004) que, trabalhando em condições semelhantes às deste estudo, mostrou através de equações quadráticas que a máxima produção de matéria seca no pleno florescimento seria obtida com 222 ( $\left.\mathrm{r}^{2}: 0,98\right), 240\left(\mathrm{r}^{2}: 0,97\right)$ e $174\left(\mathrm{r}^{2}: 0,90\right) \mathrm{kg} \mathrm{ha}^{-1}$ de $\mathrm{N}$ nos anos agrícolas 2000/01, 2001/02 e 2002/03, respectivamente, havia incremento nas concentrações de $\mathrm{N}$ e de K na parte aérea do milho, com o aumento nas doses aplicadas destes nutrientes.

A primeira análise econômica refere-se ao ponto de nivelamento, o qual representa o número de unidades que devem ser produzidas (no caso $\mathrm{kg} \mathrm{ha}^{-1}$ de grãos) para cobrir o custo total de produção, levando-se em conta um valor de comercialização prédeterminado (PAVINATO, 2004; SANTOS, 1996). O ponto de nivelamento variou entre 4.309 e $6.075 \mathrm{~kg} \mathrm{ha}^{-1}$ para o ano agrícola 2002/03 e entre 4.901 e $7.046 \mathrm{~kg} \mathrm{ha}^{-1}$ para o ano agrícola 2003/04 (Figura 2). A variação nos valores dentro de cada ano se deve à variação na dose dos fertilizantes utilizados nos tratamentos. Estes valores são considerados elevados para lavouras, sem irrigação, mas são aceitáveis e passíveis de serem cobertos e com lucro, quando consideradas áreas sob irrigação bem manejadas. A variação entre o primeiro e segundo ano foi basicamente devido à elevação do custo de fertilizantes e sementes. 


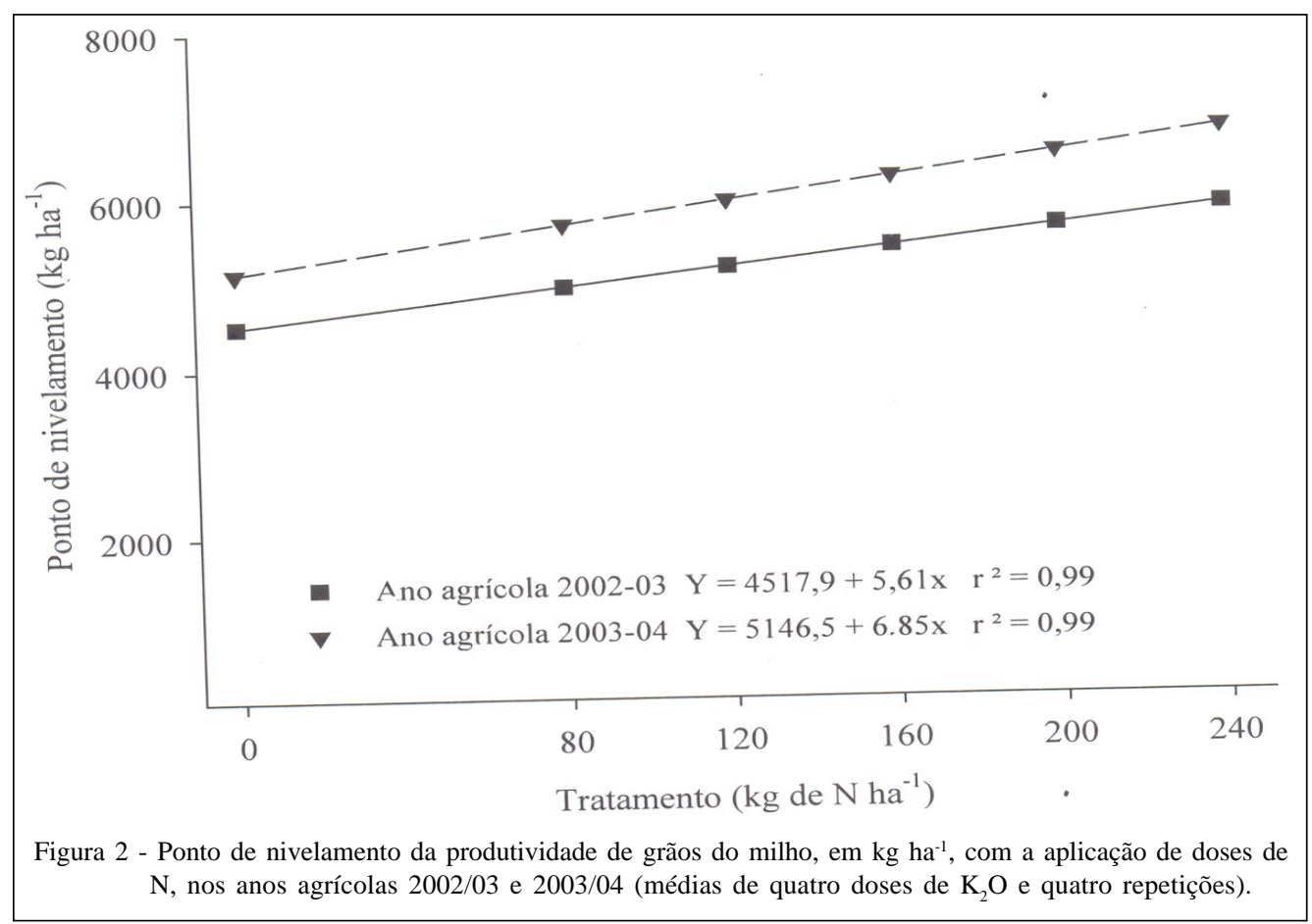

Os custos totais de produção das várias combinações de $\mathrm{N}_{\text {e }} \mathrm{K} \mathrm{O}$ variaram entre US $\$ 415,85$ e US\$ 586,23 por hectare de área produzida para o ano agrícola 2002/03 (equivalente em junho de 2003 a R \$ $1.185,17$ e R \$ 1.670,76 por hectare). Os custos variáveis de produção, incluindo os investimentos a serem feitos pelo produtor para realizar o cultivo, ficaram entre US\$ 252,75 e US $\$ 422,43$, representando 61 a $72 \%$ do custo total, sendo os valores extremos correspondentes a testemunha (sem $\mathrm{Ne} \mathrm{K}_{2} \mathrm{O}$ ) e o tratamento com as maiores doses $\left(240 \mathrm{~kg} \mathrm{ha}^{-1}\right.$ de $\mathrm{N}$ e $120 \mathrm{~kg} \mathrm{ha}^{-1}$ de $\mathrm{K}_{2} \mathrm{O}$ ), respectivamente. Para o ano agrícola 2003/04, os custos totais de produção variaram entre US\$ 486,85 e US\$ 699,95 por hectare de área produzida (equivalente em junho de 2004 a R $\$ 1.387,52$ e R \$1.994,86 por hectare). Os custos variáveis de produção no segundo ano ficaram entre US\$ 324,09 e US\$ 537,19, representando 67 a $77 \%$ do custo total de produção. Esse aumento nos custos variáveis no segundo ano foi resultante principalmente do acréscimo no custo de fertilizantes e sementes.

Os custos com adubação de $\mathrm{N}$ e $\mathrm{K}_{2} \mathrm{O}$ foram de até 29,0 e 30,5\% do custo total de produção para os dois anos agrícolas, respectivamente (Tabela 1). Tomando como exemplo uma das situações mais favoráveis para o cultivo, com $160 \mathrm{~kg} \mathrm{ha}^{-1}$ de N e $40 \mathrm{~kg}$ ha- ${ }^{-1}$ de $\mathrm{K}_{2} \mathrm{O}$, no ano agrícola 2002/03 a adubação representou $19 \%$ do custo total e $28 \%$ do custo variável, enquanto que em $2003 / 04$ foi de $20,5 \%$ do custo total e $28 \%$ do custo variável.
Apesar de não ter havido resposta significativa ao potássio, decidiu-se considerar, no cálculo da receita bruta e líquida, que o produtor aplicaria potássio e foi considerada a dose de $40 \mathrm{~kg} \mathrm{ha}^{-1} \mathrm{de} \mathrm{K}_{2} \mathrm{O}$ porque os resultados mostraram que com esta dose eram obtidos os maiores coeficientes lineares nas regressões para as doses de $\mathrm{N}$, além do fato de que seria improvável que os produtores não utilizassem adubação potássica. Contudo, se fosse considerada a recomendação da CQFS-RS/SC (2004), a reposição de $\mathrm{K}_{2} \mathrm{O}$ deveria ser de aproximadamente $60 \mathrm{~kg} \mathrm{ha}^{-1}$, considerando-se a produtividade média de grãos de milho nos dois anos.

A receita bruta aumentou com a dose de $\mathrm{Ne}$ atingiu o máximo com as doses de 243 e $248 \mathrm{~kg} \mathrm{~h}^{-1}$, com coeficiente de determinação de 0,92 e 0,81 , em 2002/ 03 e 2003/04, respectivamente, evidenciando o potencial de resposta do milho ao $\mathrm{N}$ (Figura 3). Contudo, a máxima eficiência econômica, considerando-se as curvas ajustadas, seria obtida com a aplicação de 156 e 158kg ha $^{-1}$ de N, obtendo-se receita líquida de US\$ 449,55 e US \$ 571,60ha-1 ${ }^{-1}$ nos anos agrícolas de 2002/03 e 2003/ 04 , respectivamente. Esses valores altos de receita bruta e líquida demonstram que a cultura é viável e que o cultivo sob irrigação é uma garantia de produção para o agricultor, compensando maiores investimentos no sistema produtivo. Tanto que, sob condições de sequeiro, estudos realizados por SILVA et al. (2005) com doses e épocas de aplicação de $\mathrm{N}$ mostraram que 
Tabela 1 - Custo, em US\$ ha ${ }^{-1}$, de cada combinação de doses dos fertilizantes nitrogenado e potássico, para os anos agrícolas 2002/03 e 2003/04*.

\begin{tabular}{|c|c|c|c|c|c|c|}
\hline \multirow{2}{*}{$\mathrm{K}_{2} \mathrm{O}\left(\mathrm{kg} \mathrm{ha}^{-1}\right)$} & \multicolumn{6}{|c|}{ Nitrogênio $\left(\mathrm{kg} \mathrm{ha}^{-1}\right)$} \\
\hline & 0 & 80 & 120 & 160 & 200 & 240 \\
\hline \multicolumn{7}{|c|}{ Ano agrícola 2002/03 } \\
\hline 0 & 0,00 & 43,04 & 64,56 & 86,08 & 107,60 & 129,12 \\
\hline 40 & 13,52 & 56,56 & 78,08 & 99,60 & 121,12 & 142,64 \\
\hline 80 & 27,04 & 70,08 & 91,60 & 113,12 & 134,64 & 156,16 \\
\hline 120 & 40,56 & 83,60 & 105,12 & 126,64 & 148,16 & 169,68 \\
\hline \multicolumn{7}{|c|}{ Ano agrícola 2003/04 } \\
\hline 0 & 0,00 & 54,26 & 81,39 & 108,52 & 135,64 & 162,77 \\
\hline 40 & 16,84 & 71,10 & 98,23 & 125,36 & 152,48 & 179,61 \\
\hline 80 & 33,68 & 87,94 & 115,07 & 142,20 & 169,32 & 196,45 \\
\hline 120 & 50,52 & 104,78 & 132,01 & 159,14 & 186,26 & 213,39 \\
\hline
\end{tabular}

* Custos estimados tendo por base os preços da tonelada de uréia de US\$ 242,11 e 305,26 e da tonelada de KCl de US\$ 202,81 e 252,43, para os anos de 2002/03 e 2003/04, respectivamente. Valores coletados juntos a empresas fornecedoras da região onde foi conduzido o trabalho.

a máxima eficiência econômica foi alcançada com a dose de $126 \mathrm{~kg} \mathrm{ha}^{-1}$ de $\mathrm{N}$, aplicando-se metade na semeadura e metade no estádio de 4 a 6 folhas.

Os resultados deste trabalho mostram que, em geral, doses entre 120 e $160 \mathrm{~kg} \mathrm{ha}^{-1}$ de $\mathrm{N}$ podem ser tomadas como base para altas produtividades de grãos e maior retorno econômico para a cultura do milho. Dados da literatura fundamentam estas doses de $\mathrm{N}$, pois várias recomendações citam intervalos próximos ou semelhantes aos valores obtidos neste trabalho.
No ano agrícola de 2001/02, SILVEIRA(2002) mostrou que a aplicação de $160 \mathrm{~kg} \mathrm{ha}^{-1}$ de $\mathrm{N}$ proporcionou maior retorno econômico para o produtor. CANTARELLA (1993) menciona que, para várias regiões do Brasil e do exterior, a recomendação de N para a cultura do milho, objetivando altas produtividades (mais de $9.000 \mathrm{~kg} \mathrm{ha}^{-1}$ ), varia de 150 a $300 \mathrm{~kg} \mathrm{ha}^{-1}$, sendo este intervalo amplo e acima dos 156 e $158 \mathrm{~kg} \mathrm{ha}^{-1}$, correspodentes à máxima eficiência econômica obtida no presente trabalho, cujos valores representam praticamente a média da

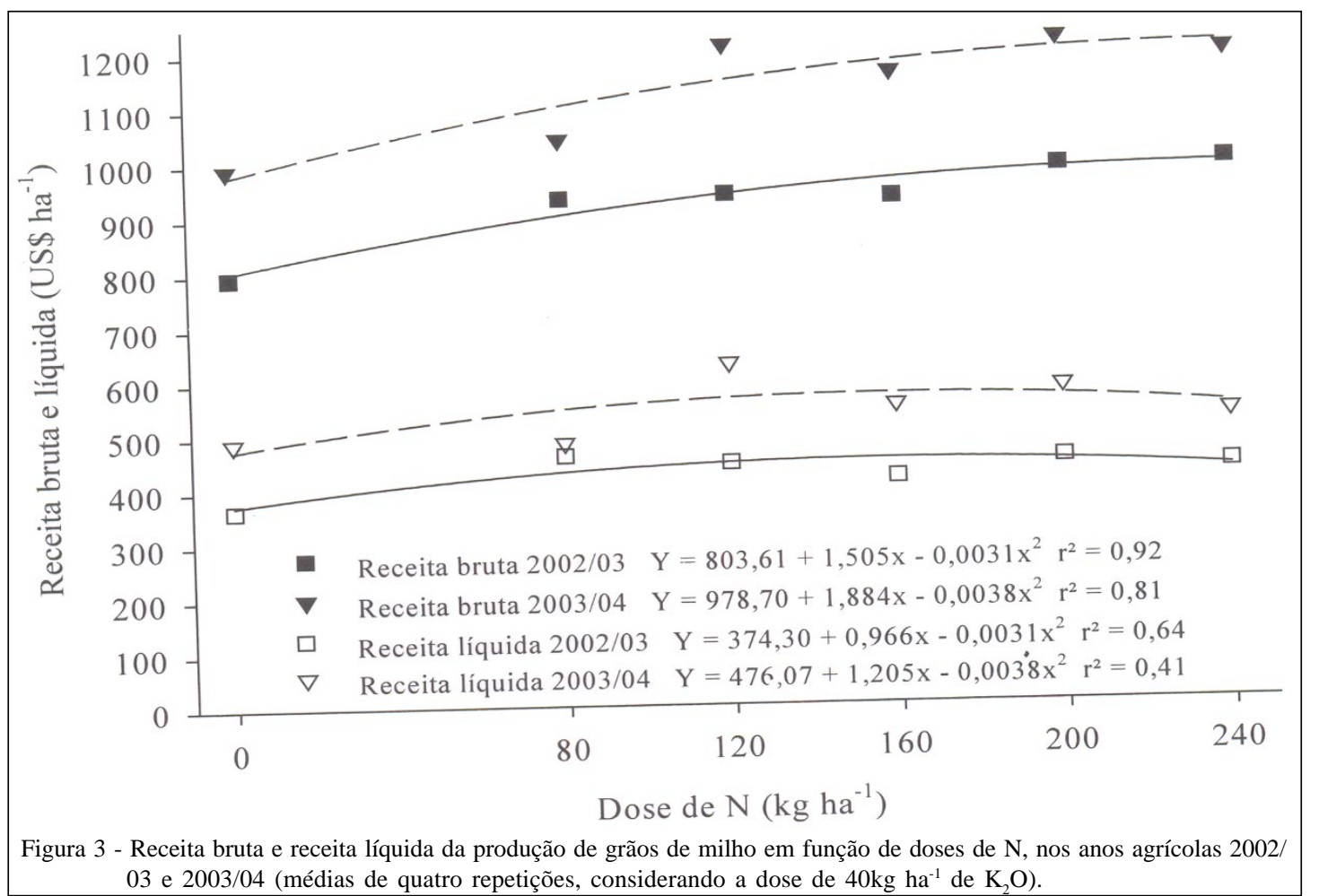

Ciência Rural, v.38, n.2, mar-abr, 2008. 
recomendação das doses de 100 a $200 \mathrm{~kg} \mathrm{ha}^{-1}$ de $\mathrm{N}$ para milho irrigado, feita por COELHO \& FRANÇA (1999). As doses de máxima eficiência econômica, obtidas no presente trabalho, são similares às indicadas no manual de adubação e de calagem para o estado do RS e de SC (CQFS-RS/SC, 2004) para produtividades médias de $10.000 \mathrm{~kg} \mathrm{ha}^{-1}$ de grãos de milho, cultivados após gramínea com produtividade média de matéria seca, pois, neste caso, a recomendação seria de $160 \mathrm{~kg} \mathrm{ha}^{-1}$ de $\mathrm{N}$, demonstrando que os valores estão ajustados à produção de milho sob irrigação.

\section{CONCLUSÕES}

A máxima produtividade de grãos de milho sob irrigação por aspersão é obtida com a aplicação de 283 a 289 $\mathrm{kg} \mathrm{ha}^{-1}$ de nitrogênio, mas a máxima eficiência econômica ocorre com 156 a 158kg ha ${ }^{-1}$ de nitrogênio, não havendo incremento na produtividade com a aplicação de potássio, quando os teores de potássio disponível no solo estão em nível muito alto. Isso evidencia que, em muitas situações, os produtores estão utilizando fertilizantes nitrogenados e potássicos acima do necessário.

\section{AGRADECIMENTOS}

À empresa Pionner Sementes, pela concessão das áreas para os experimentos e pelo auxílio na condução através dos Engenheiros Agrônomos Volmir Goulart, Fernando Zimmermann, André Keller da Silva e Itavor Nummer. À empresa SLC Agrícola Ltda, pelo fornecimento de dados para compor o cálculo de custos de produção, em especial ao Engenheiro Agrônomo Aurélio Pavinato. Ao Conselho Nacional de Desenvolvimento Científico e Tecnológico (CNPq), pela concessão de bolsa aos pesquisadores Ceretta, Girotto e Moreira.

\section{REFERÊNCIAS}

AMADO, T. et al. Recomendação de adubação nitrogenada para o milho no RS e SC adaptada ao uso de culturas de cobertura do solo, sob sistema plantio direto. Revista Brasileira de Ciência do Solo, v.26, n.1, p.241-248, 2002.

ARAUJO, L.A.N. et al. Adubação nitrogenada na cultura do milho. Pesquisa Agropecuária Brasileira, v.39, n.8, p.771777, 2004.

CANTARELLA, H. Calagem e adubação do milho. In: BÜLL, L.T.; CANTARELLA, H. (Ed.). Cultura do milho: fatores que afetam a produtividade. Piracicaba: POTAFOS, 1993. p.147-185.

CERETTA, C.A.; PAVINATO, P.S. Adubação em linha ou a lanço no plantio direto. In: CURSO DE FERTILIDADE DO SOLO EM PLANTIO DIRETO, 6., 2003, Ibirubá, RS. Anais... Passo Fundo: Aldeia Norte, 2003. p.23-35.
CERETTA, C.A.; SILVEIRA, M.J. Manejo da fertilidade do solo para altas produtividades. In: CARLESSO, R. et al. (Ed.). Irrigação por aspersão no Rio Grande do Sul. Santa Maria: UFSM, 2001. p.10-20.

CHRISTOFIDIS, D. Irrigação, a fronteira hídrica na produção de alimentos. Revista ITEM (Irrigação \& Tecnologia Moderna), n.54, p.46-55, 2002.

COELHO, A.M.; FRANÇA, G.E. Nutrição e adubação do milho, 1999. Capturado em 22 nov. 2001. Online. Disponível na Internet: www.cnpms.embrapa.br/deficiencia/deficiencia/ html.

COMISSÃO DE QUIMICA E FERTILIDADE DO SOLO (CQFS RS/SC). Manual de adubação e de calagem para os estados do Rio Grande do Sul e Santa Catarina. 10.ed. Porto Alegre: Sociedade Brasileira de Ciência do Solo/Núcleo Regional Sul, 2004. 400p.

EMPRESA BRASILEIRA DE PESQUISA AGROPECUÁRIA EMBRAPA. Sistema brasileiro de classificação de solos. Brasília: Embrapa Produção de Informação. Rio de Janeiro: Embrapa Solos, 1999. 412p.

FERNANDES, L.A. et al. Preparo do solo e adubação nitrogenada na produção de grãos e matéria seca e acúmulo de nutrientes pelo milho. Pesquisa Agropecuária Brasileira, v.34, n.9, p.1691-1698, 1999.

FORNASIERI, D.F. A cultura do milho. Jaboticabal: FUNEP, 1992. 273p.

LINK, J. et al. Evaluating the economic and environmental impact of environmental compensation payment policy under uniform and variable-rate nitrogen management. Agricultural Systems, v.91, p.135-153, 2006.

MENDONÇA, F.C. et al. Adubação nitrogenada do milho em um sistema de irrigação por aspersão em linha. Scientia Agricola, v.56, n.4, p.1035-1044, 1999.

PAVINATO, P.S. Adubação em sistemas de culturas com milho em condições de sequeiro ou irrigado por aspersão. 2004. 71f. Dissertação (Mestrado em Ciência do Solo) - Curso de Pós-graduação em Ciência do Solo, Universidade Federal de Santa Maria.

SANTOS, G.J. Administração de custos na agropecuária. 2.ed. São Paulo: Atlas, 1996. 139p.

SAS INSTITUTE (Cary, Estados Unidos). The SAS System for Windows 6.11 (software). Cary, 1996. CD-ROM.

SILVEIRA, M.J. Produtividade e análise econômica da utilização de nitrogênio e potássio em milho irrigado por aspersão. 2002. 67f. Dissertação (Mestrado em Agronomia) - Curso de Pós-graduação em Agronomia, Universidade Federal de Santa Maria.

SILVA, E.C. et al. Doses e épocas de aplicação de nitrogênio na cultura do milho em plantio direto sobre Latossolo Vermelho. Revista Brasileira de Ciência do Solo, v.29, n.3, p.353362, 2005.

SILVA, E.C.et al. Manejo de nitrogênio no milho sob plantio direto com diferentes plantas de cobertura, em Latossolo Vermelho. Pesquisa Agropecuária Brasileira, v.41, n.3, p.477-486, 2006. 